\title{
Investigation of Abrasive Wear Behavior of Industrial Wastes on Al 6061 Material Using Rubber Wheel Abrasion Test (RWAT) Method
}

\author{
Mustafa Sabri GOK *, Hanife OZLIMAN \\ Faculty of Engineering, Bartin University 74100 Bartin, Turkey \\ crossref http://dx.doi.org/10.5755/j01.ms.25.1.19181
}

Received 02 October 2017; accepted 19 January 2018

\begin{abstract}
In this study, the abrading characteristics of the slags, generated in the form of industrial waste during raw iron, steel and ferrochromium ore production, are investigated. Granulated blast furnace slag (GBFS), basic oxygen furnace slag (BOF) ferrochromium slag (FCS) and commercial $\mathrm{Al}_{2} \mathrm{O}_{3}$ powder were used during the tests. Abrasion tests were conducted using Rubber Wheel Abrasion Wear (RWAT) method. Al 6061 was chosen as the counter body material. The tests were conducted under 25, 50, 75 and $100 \mathrm{~N}$ loads with $100 \mathrm{r} / \mathrm{min}$ rubber wheel rotational speed. The highest rate of abrasion was obtained from GBFS under all loads as a result of the conducted tests. Under high loads, the abrading performance of FCS reached that of the commercial $\mathrm{Al}_{2} \mathrm{O}_{3}$ powder. $\mathrm{BOF}$ was found to have no abrading capability. Surface morphology and SPQ (spike parameter-quadratic fit) value were as effective as the particle hardness in the evaluation of abrading performance. As dominant wear mechanisms, spalling, ploughing and micro-scratch formation were observed on the specimens abraded with GBFS and $\mathrm{Al}_{2} \mathrm{O}_{3}$, whereas severe plastic deformation-induced extrusion was observed on the specimen abraded with FCS.

Keywords: ferrochromium slag, recycling, waste, RWAT, SPQ, wear.
\end{abstract}

\section{INTRODUCTION}

Waste products can be defined as useless and harmful materials generated as a result of manufacturing and utilization activities. Industrial solid wastes are the solid by-products of industrial and manufacturing processes that require disposal for health and environmental purposes. Recently, the storage of metals with economic value, as well as the waste products of such metals occurring as a result of their processing, hold great importance [1-4]. A considerable amount of waste, equivalent to the amount of the produced raw material, occur particularly in the mining industry. Some of these solid wastes pose serious environmental hazards.

Industrial slags with oxide content are the unavoidable by-products of extractive metallurgy operations. These materials pose a wide range of health and environmental hazards. Slags can be categorized in three groups. These are ferro-slags, non-ferro-slags and combustion slags. Ferro-slags are produced during iron steel production and they account for $1 / 5$ of the semi-processed product. Granulated blast furnace, basic oxygen furnace and ferrochromium slag are produced as waste/ byproduct during the production of raw iron, steel and stainless steel products. Such types of slag consist of heterogeneous oxide materials and they are primarily composed of species containing iron, calcium, aluminum and silicon [5-9]. Abrasives are sharp-edged hard particles, standardized at different sizes. They are used as abrader and reinforcing agent for materials with high wear resistance, due to their high hardness and chemical stability [10]. Alumina and silicon carbide are widely used as abrasive materials due to their ability to adapt to different compositions and their

\footnotetext{
* Corresponding author. Tel.: +90-378-5011000; fax: +90-378-5011021.

E-mail address: m.sabrigok@gmail.com (M.S. Gok)
}

availability. Abrasives such as diamond and cubic boron nitride, preferred in a wide range of applications, exhibit superior properties such as high hardness and wear resistance beside their disadvantages such as their high cost.

In the last decades, the by-products (basic oxygen furnace slag and electric arc furnace slag) from the steel industry have attracted considerable interest from researchers for use as wetland substrates after various tests such as batch tests and field tests. Accordingly, investigation of the abrading characteristic of the slags generated during the production of raw iron, steel and ferrochromium ore, is aimed in the present study. Various researches have been conducted in different fields of science on slags and their use in different applications [11-18]. There has been a great amount of ferrochromium slag deposit in the site. In point of recycling, the FeCr slag has been evaluated in the production of concrete but its usage area need to be increased [19]. A vast number of studies is available in the literature on determination of abrasion resistance of several materials using commercial abrasives, though no research was encountered as to the abrasive characteristic of slags available as industrial waste.

\section{EXPERIMENTAL}

\subsection{ASTM G65 dry sand/rubber wheel wear resistance test}

Abrasion tests were conducted under dry conditions with a test rig having ASTM G-65 standard (ASTMG 65-04, 2010). Simple schematic diagram of the test rig is given in Fig. 1. 


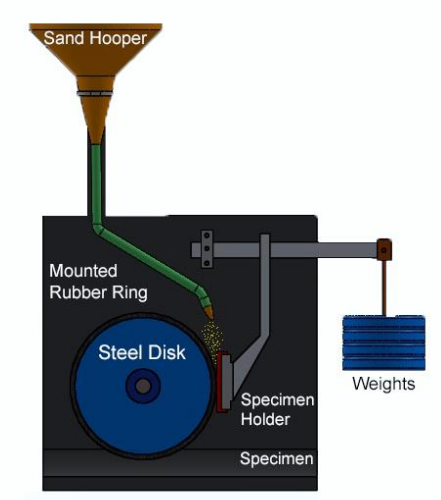

Fig. 1. Schematic diagram of RWAT testing device

The tests were conducted under 25, 50, 75 and $100 \mathrm{~N}$ loads. Rubber Wheel rotational speed was specified as $100 \mathrm{r} / \mathrm{min}$. Powder feeding rate was $250 \pm 10 \mathrm{~g} / \mathrm{min}$. The dimension at the end of the powder feeding nozzle was modified to provide uniform flow rate of the powder. To overcome the flow ability problem of FCS powder, the powder in the feed funnel was blended with a mixer. Sliding distances were specified as 75, 150 and $225 \mathrm{~m}$. For comparison of abrasive wear performance of the industrial wastes, the samples were also subjected to abrasive wear tests using $\mathrm{Al}_{2} \mathrm{O}_{3}$ (AFS 60) as abrasive material. Mass loss of the specimens were measured using an electronic scale with $10-4$ sensitivity.

\subsection{Test materials}

In the present study, Al 6061 alloy with $75 \times 25 \times 10 \mathrm{~mm}$ dimensions was used as the counter (worn) surface. The microstructural details of Al 6061 are described elsewhere. Brinell hardness of the alloy was measured as $30 \mathrm{HB}$. Prior to the abrasion process, surface roughness of $\mathrm{Al} 6061$ was determined as $\mathrm{Ra}=0.2-0.3 \mu \mathrm{m}$. Surfaces of the specimens, prepared using a hydraulic sleeved saw in above-stated dimensions, were cleaned with pressurized air. Afterwards, the specimens were fixed on an ASTM G 65 type abrasive wear test rig. After the abrading process, specimen surfaces were cleaned with pressurized air for a more accurate determination of the wear loss. Each abrasion test was repeated 3 times as a means for minimization of the error margin and their mean value were taken into calculation.

\subsection{Abrasive materials}

The industrial wastes, abrasive properties of which were to be determined, were obtained from the industrial facilities in Turkey. GBFS and BOF slags were obtained from Eregli Iron and Steel Works Co., and FCS was obtained from Elazig ferrochromium facilities. The wastes were brought in the laboratory in $25 \mathrm{~kg}$ sacks. The granular wastes in the particle size range of $50-1500 \mu \mathrm{m}$, were subjected to single sieving with $500 \mu \mathrm{m}$ mesh dimension. Commercial $\mathrm{Al}_{2} \mathrm{O}_{3}$ powders were purchased in AFS 60 standard.

After the sizing process, SEM analysis (TESCAN brand scanning electron microscope equipped with Energy
Dispersive Spectroscopy (EDS) capability) was conducted to determine the surface morphologies of industrial wastes. The images obtained from the powder particles in secondary electron format, are respectively given in Fig. 2.

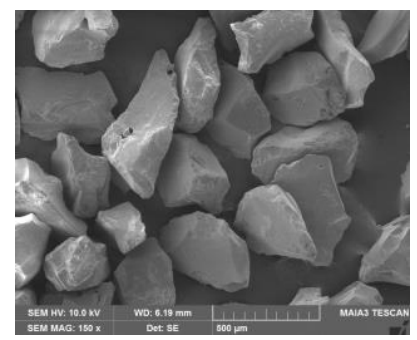

a



c

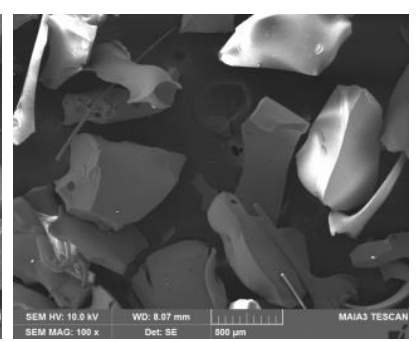

$\mathrm{b}$
Fig. 2. Abrasive powder particles: $\mathrm{a}-\mathrm{Al}_{2} \mathrm{O}_{3}$ particles; $\mathrm{b}$ - granulated blast furnace slag; $\mathrm{c}$-ferrochromium slag; $\mathrm{d}$-blast furnace slag

The edged and smooth structure of $\mathrm{Al}_{2} \mathrm{O}_{3}$ powders is seen in Fig. 2 a. In Fig. 2 b, GBFS powders seem to have a more edged and cornered structure as compared to $\mathrm{Al}_{2} \mathrm{O}_{3}$. The structure of ferrochromium slag (Fig. 2 c) features smoother edges and corners with a varying particle morphology. A lamellar, global structure without sharp edges, is observed in the SEM image of basic oxygen furnace slag (Fig. 2 d). X-ray fluorescence (XRF) analyses were carried out to determine the chemical composition of the slags. In XRF analysis, fusion melt technique was used. Slag powders were melted with lithium tetraborate compound to dilute the powder mixture and then the melt tablet of $40 \mathrm{~mm}$ diameter were analysed in XRF. The results of XRF analyses are given in Table 1.

Table 1. Chemical composition of slags

\begin{tabular}{|l|c|c|c|c|}
\hline \multirow{2}{*}{$\begin{array}{l}\text { Chemical } \\
\text { composition }\end{array}$} & \multicolumn{4}{|c|}{ Percentage in weight, \% } \\
\cline { 2 - 5 } & GBFS & FCS & BOF & $\mathrm{Al}_{2} \mathrm{O}_{3}$ \\
\hline $\mathrm{SiO}_{2}$ & 39.99 & 28.48 & 17.62 & - \\
\hline $\mathrm{Al}_{2} \mathrm{O}_{3}$ & 10.51 & 21.59 & 4.03 & 98.51 \\
\hline $\mathrm{Fe}_{2} \mathrm{O}_{3}$ & 3.49 & 3.51 & 23.81 & 0.41 \\
\hline $\mathrm{CaO}$ & 5.95 & 36.52 & 4.56 & - \\
\hline $\mathrm{MgO}$ & 0.27 & 0.03 & 1.10 & - \\
\hline $\mathrm{SO}_{3}$ & - & 0.60 & 12.99 & - \\
\hline $\mathrm{Loss}_{3}$ on ignition & 0.58 & 0.25 & 0.33 & 0.40 \\
\hline $\mathrm{Na}_{2} \mathrm{O}$ & 1.30 & 0.21 & 0.27 & - \\
\hline $\mathrm{K}_{2} \mathrm{O}$ & 0.021 & 6.950 & 0.138 & 0.053 \\
\hline $\mathrm{Cr}_{2} \mathrm{O}_{3}$ & 3.550 & 0.200 & 3.040 & 0.020 \\
\hline $\mathrm{Mn}_{2} \mathrm{O}_{3}$ & 0.0 & 0.0 & 0.466 & 0.0 \\
\hline $\mathrm{P}_{2} \mathrm{O}_{5}$ & 1.224 & 0.329 & 0.392 & 0.009 \\
\hline $\mathrm{TiO}_{2}$ & - & - & - & - \\
\hline $\mathrm{Cr}^{\mathrm{Un} n d e r t e m i n a t e d}$ & 1.57 & 0.71 & 0.86 & 0.39 \\
\hline $\mathrm{Total}$ & 98.44 & 99.29 & 99.14 & 99.61 \\
\hline $\mathrm{Specific}$ weight & 3.91 & 3.25 & 2.81 & 2.89 \\
\hline
\end{tabular}




\subsection{Hardness measurements}

Qness brand (Austria) microhardness device was used to evaluate the hardness values of the slag particles. Measurements were conducted in VICKERS mode of the device. Slag particles were hot mounted in bakelite moulds with $20 \times 10 \mathrm{~mm}$ dimensions. Afterwards, the mounted specimens were ground in 80-2000 mesh range and then polished to obtain smooth surfaces prior to measurement. The measurements were conducted with $100 \mathrm{~g}$ load and $5 \mathrm{~s}$ loading period, 10 measurements were taken from each specimen and their mean values were taken into evaluation.

\section{DISCUSSION}

During the abrading process carried out with RWAT test method using industrial wastes, Al 6061 countersurface material exhibited varying mass loss values under the same load and sliding distance parameters. Hardness values of the used industrial waste and commercial $\mathrm{Al}_{2} \mathrm{O}_{3}$ abrasive particles are in the following order: $\mathrm{BOF}<\mathrm{FCS}<\mathrm{GBFS}<\mathrm{Al}_{2} \mathrm{O}_{3}$ (Table 2).

Table 2. Hardness values of slags

\begin{tabular}{|c|c|c|c|c|c|}
\hline Slug name & GBFS & FCS & BOFSS & $\mathrm{Al}_{2} \mathrm{O}_{3}$ & $\mathrm{Al} 6061$ \\
\hline Hardness & $910 \mathrm{HV}$ & $1050 \mathrm{HV}$ & $600 \mathrm{HV}$ & $2000 \mathrm{HV}$ & $30 \mathrm{HB}$ \\
\hline
\end{tabular}

In this study, the hardness values and abrading characteristics of the specimens did not exhibit a direct relation. The hardness, size and angularity of the abrasive particle under load play a major role in the abrading process. It was also reported by many researchers that, ratio of hardness $(\mathrm{Ha} / \mathrm{Hm})$ between the abrasive $(\mathrm{Ha})$ and hardmetal $(\mathrm{Hm})$ can govern the wear mechanism during three-body abrasion [21-24]. However, in the present study, since the $\mathrm{Ha} / \mathrm{Hm}$ rates between the abrasives and $\mathrm{Al}$ 6061 were found to be significantly high, the abrasive behavior of the particle is ascribed to its angularity and morphology.

GBFS exhibited the highest abrasion rates under all load and distance parameters for Al 6061 alloy, as observed in the SEM images of GBFS particle given in Fig. 2 b. As seen in the figure, the particles consist of acute angled sharp cornered surfaces. As seen in Table 3, the highest SPQ value also belongs to this specimen. The first contact of abrading particle with the counter body occurs at its hard and sharp edges, which defines the spatial distribution of cutting edges and points, relative to a work piece and the magnitude of the apex angles. This, in turn, results in a higher rate of material removal by the abrading particle from the counter surface.

Several methods are used in characterization of the particle shape [25-27]. Two of the methods used in angularity analysis of powder particles are 'spike parameter-linear fit' (SP) and 'spike parameter-quadratic fit' (SPQ). In depth information as to these methods can be found in the literature [28-31], SPQ method was developed in an effort to remedy some of the deficiencies of SP method. The high angularity of powder particles used in both two body and three body abrasion processes has a major impact on the exhibited wear behavior. A linear relationship between the increase in particle angularity and the increase in abrasive wear rates was reported in a previous research as a result of the conducted experiments [31]. A similar situation was also observed in the present study, as GBFS's higher three body abrasion rate than commercial $\mathrm{Al}_{2} \mathrm{O}_{3}$, despite its lower hardness, is correlated with the high SPQ value of the abrasive particles.

Table 3. Particle shape, SPQ values and 3D surface views

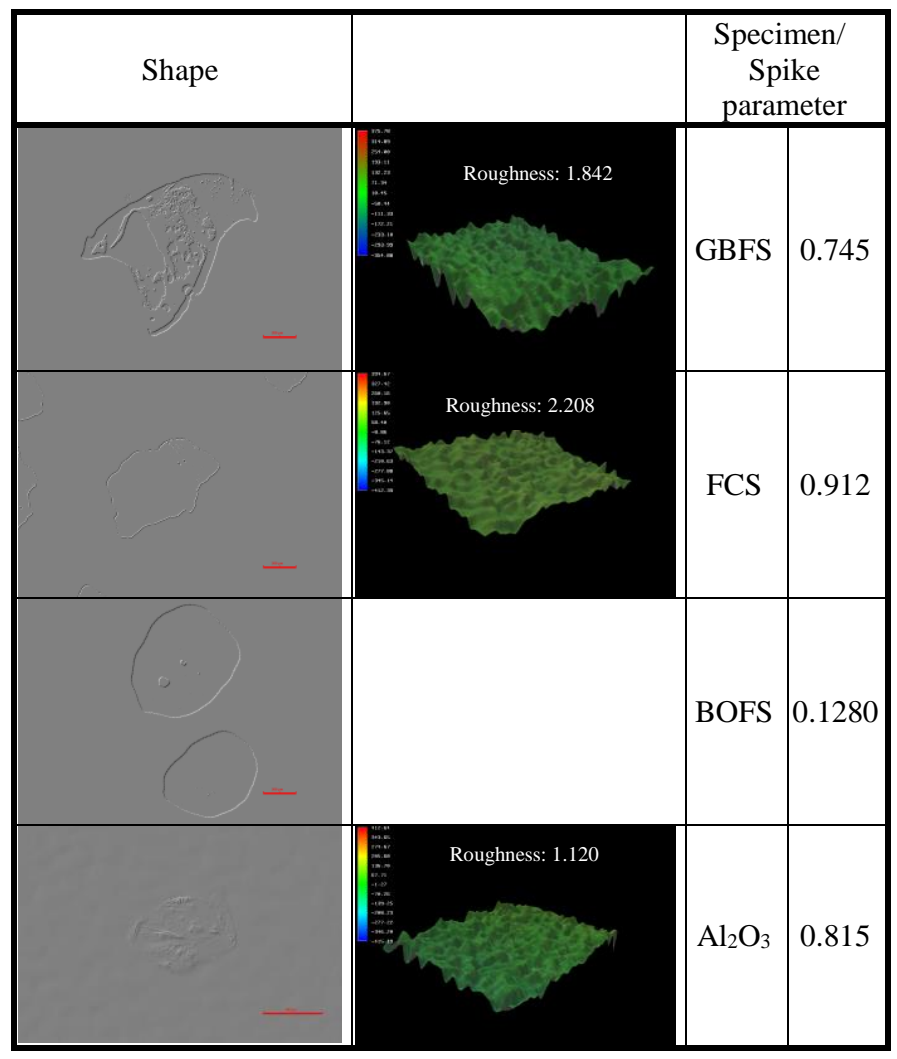

Under 25 and $50 \mathrm{~N}$ loads, FCS exhibited a similar abrasion behavior with $\mathrm{Al}_{2} \mathrm{O}_{3}$ in terms of wear loss. However, under 75 and $100 \mathrm{~N}$ loads, FCS induced a higher rate of material transfer as seen in the graph (See Fig. 3).

The abrading characteristic of FCS even reached GBFS under these loads. Despite having the lowest SPQ value among the abrasive particles (when BOF is neglected), FCS's higher abrasion rates under high loads can be explained as follows.

Lower wear loss is observed under lower loads when FCS is compared with GBFS and $\mathrm{Al}_{2} \mathrm{O}_{3}$, since the cutting edges of FCS particles are rounder with an indented morphology. The high abrasion rate exhibited by FCS particles under 75 and $100 \mathrm{~N}$ loads can be explained by a number of theories. According to the first theory, the force exerted on the particles stuck between the rubber wheel and the counter body, will be higher depending on the increasing load. Accordingly, the indentation depth of the particle on the counter surface will also increase and the downward movement of the rubber wheel will induce a higher shearing force, which in turn results in a higher rate of material transfer. According to the second theory, the FCS particles stuck between the rubber wheel and the counter body, are split with increasing load, leading to the 
formation of more new cutting surfaces which increases the abrading capability of the particle. This theory is supported by the SEM images of the particles taken before and after the abrasion tests (Fig. 4).


$\mathrm{b}$

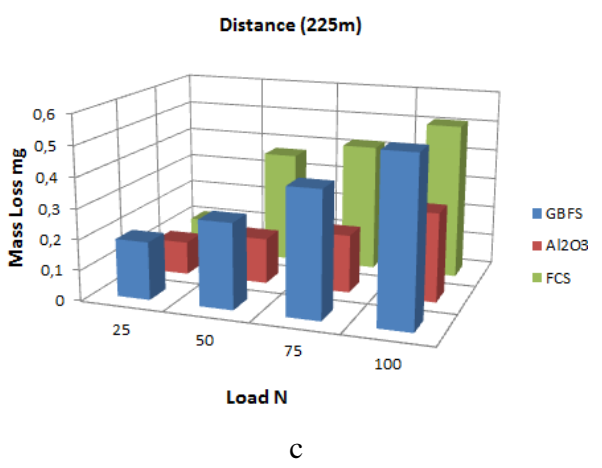

Fig. 3. Abrasive type-wear loss graph: a-75 $\mathrm{m}$ distance; $\mathrm{b}-150 \mathrm{~m}$ distance; $\mathrm{c}-225 \mathrm{~m}$ distance

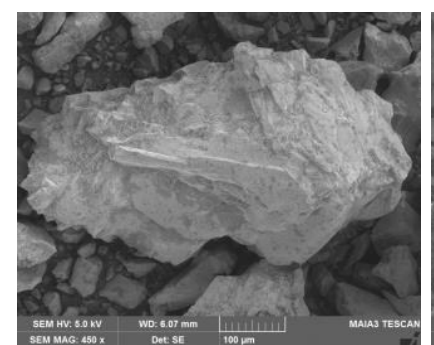

a

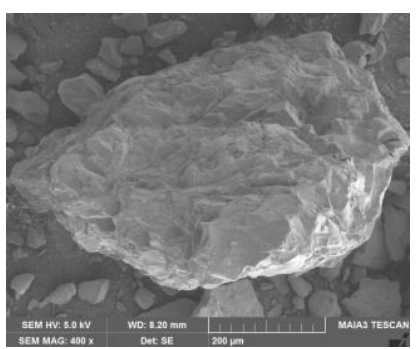

b
Fig. 4. $a$ - unused FCS particle; b-FCS particle, subject to testing under $100 \mathrm{~N}$

According to the third theory, after the splitting of the particle, the newly formed cutting edges enable a better mechanical interlocking between the FCS particles and the rubber wheel with additional help of the exerted force. As a result of such interlocking, the counter-surface of the particle also removed more material. This is schematically explained in Fig. 5.
It is reported in the literature that an increase in the hardness of the abrasive particle also increases the wear loss. In an evaluation of the wear losses depending on the abrasive hardness, the highest particle hardness belongs to $\mathrm{Al}_{2} \mathrm{O}_{3}$ abrasive particles, whereas the highest abrasion rate belongs to the specimens abraded with GBFS. Also, at upper levels, FCS exhibited an increased abrading performance, however the abrading performance of GBFS could not be associated with hardness. This is attributed to the fact that, GBFS exhibited the highest abrading performance under all loads despite having a lower hardness than FCS. This is also ascribed to the abrasive morphology, beside its hardness. It was previously stated that BOF had no abrading capability.

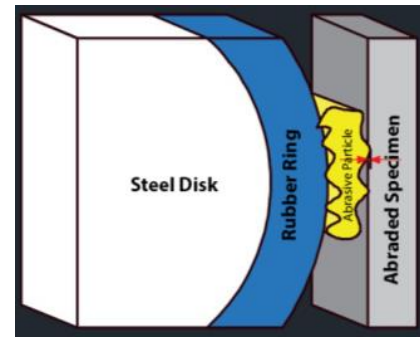

a

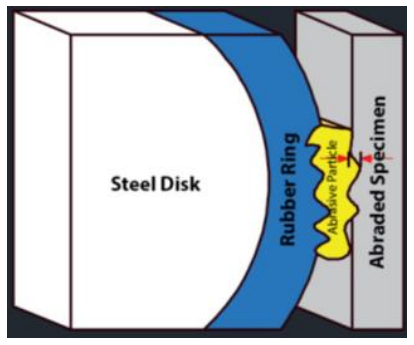

b
Fig. 5. $\mathrm{a}$-the abrasive particle under $25 \mathrm{~N}$ load; $\mathrm{b}$-the abrasive particle under $100 \mathrm{~N}$ load

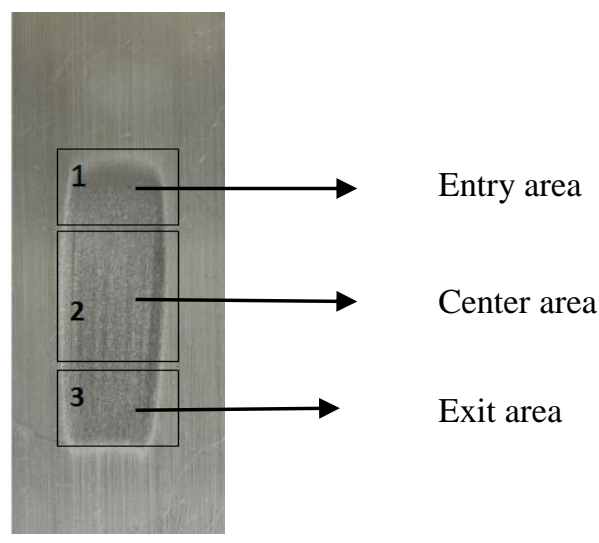

Fig. 6. Typical appearance of wear scars on specimens

The image of the typical wear track taken from the surface of AL 6061 after ASTM G 65 wear tests, is given in Fig. 6. As previously reported in the literature [37-39], the worn region can be examined at three different fields. These fields, also marked in Fig. 6, are denoted as entry (1), center (2) and exit (3). The wear mechanisms at the entry and exit areas of the worn specimens showed similarities. Occurrence of this rolling type mechanism can be explained as follows: The abrasive particles in the entry and exit areas are under the lowest loads. On the other hand, characteristics of the abrasive particle, particle movements and their interaction with rubber wheel are the effective factors in the course of wear process. Grooving type abrasion is observed if the abrasive particle's movement is restricted between the rubber wheel and the specimen, or if a protrusion acts as a fixed asperity as in two body abrasion. A similar situation was observed in the conducted research.

Different wear mechanisms were observed at the central area, where the test specimens are exposed to the 
highest loads. As seen in the SEM image of the central area of the specimen worn with $\mathrm{Al}_{2} \mathrm{O}_{3}$ (Fig. 7), ploughing and spalling are the dominant wear mechanisms in this region. In three-body abrasion, the abrasive particles move freely between the interacting surfaces by rolling and sliding movements. The wear mechanism, induced by these abrasives on the metallic surface, is closely related with the attack angle. Below a critical attack angle, the metallic material is mainly exposed to elastic-plastic deformation and it moves around and beneath the sliding particle but no material is removed from the surface. Increasing the attack angle leads to a shifting from microploughing to micro-scratch formation, i.e. material flows up the front face of the abrasive particle and it is detached from the worn surface in a chip form. A similar situation is observed on the specimens worn with $\mathrm{Al}_{2} \mathrm{O}_{3}$.



Fig. 7. Surface image of the specimen abraded under $100 \mathrm{~N}$ load $\left(\mathrm{Al}_{2} \mathrm{O}_{3}\right)$

Surfaces of the specimens, abraded with FCS, were exposed to severe deformation in extrusion form, as seen in Fig. 8.

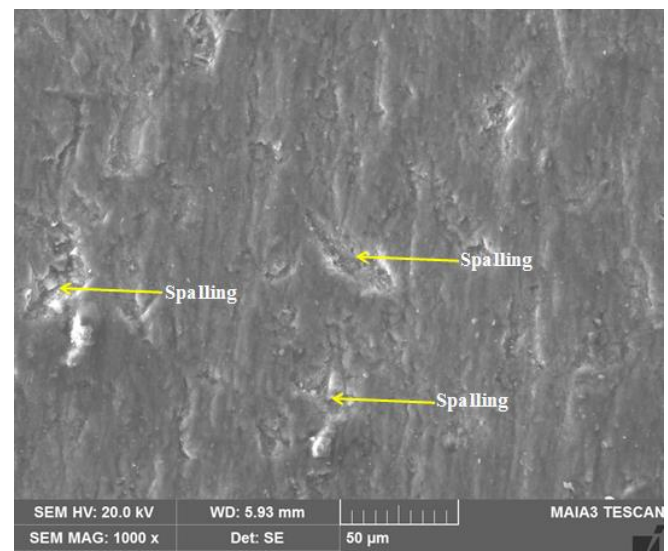

Fig. 8. Surface image of the specimen abraded under $100 \mathrm{~N}$ load (FCS)

Several tribological phenomena as abrasion, temperature rise, fracture, fatigue, plastic and elastic deformation occur during the interaction between the abrasive particle and the solid surface. As seen in the SEM images of the particles, FCS particles do not have sharp angles and exhibit a spheroid, yet rough structure. These particles, stuck between the rubber wheel and the solid surface, feature an eased rolling motion, though they have a restricted sliding capability. The particle, forced to make sliding motion at the interface, and accordingly inducing a material removal in the form of ploughing rather than cutting, results in an increase in the temperature of the specimen surface. The increased temperature of the solid surface results in a reduced yield stress, and in turn induces a higher rate of plastic deformation.

A similar wear structure with that of the specimen worn with $\mathrm{Al}_{2} \mathrm{O}_{3}$, is observed (Fig. 9) in the SEM image of the specimen surface worn with GBFS, which induces the highest abrasion rate. Here, ploughing is observed with a width of $10-25 \mu \mathrm{m}$. The layer formations on the specimen surface resulting from local plastic deformation, as well as the presence of spalling occurring as a result of particle detachment from the surface, are also visible

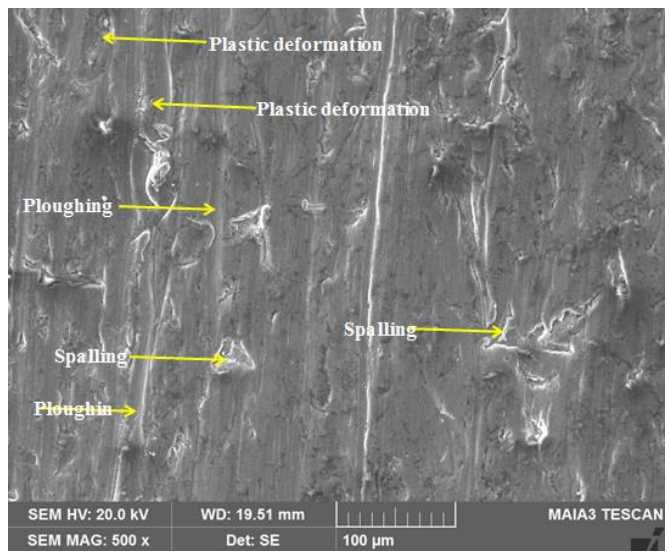

Fig. 9. Surface image of the specimen abraded under $100 \mathrm{~N}$ load (GBFS)

3D white-light interfering surface profiles, taken from the 3rd area of the specimens, abraded with different types of abrasives, are respectively given in Table 3. Ra roughness measurements, taken from these surfaces, indicate that the highest level of roughness is displayed by the specimens abraded with FCS. The lowest roughness value is observed on the specimen abraded with commercial $\mathrm{Al}_{2} \mathrm{O}_{3}$.

\section{CONCLUSIONS}

The following conclusions were drawn as a result of the RWAT tests conducted on Al 6061 material using industrial waste slags:

The usage of BOF presents no abrasive effect on $\mathrm{Al}$ 6061. In this respect, it can be clearly understood that the BOF cannot be used to abrade the materials due to the fragile structure of the BOF under load while other two slags (FCS and GBFS) can be evaluated as abrasive materials. The FCS has a roughness structure. The GBFS has sharp edges. The roughness and sharp edges of these slags provide them a high abrasive characteristic. Even GBFS presents an abrasive effect as far as a commercial product, $\mathrm{Al}_{2} \mathrm{O}_{3}$ due to this characteristic. The morphology of the abrasive particle has an important aspect in abrading process as well as hardness of the abrasive particle. When these aspects combine, they offer great potential for abrading soft materials like Al 6061 for their usage in the industries without increasing the cost. The load applied in the wear test is very important. The mass losses present an increasing trend in the increment in the load. In the first 
contact section of the abrasive particles on the material, wear mechanism seems as grooving and rolling types while spalling, ploughing and plastic deformation type wears seem in the central area.

\section{REFERENCES}

1. Cossu, R., Motzo, G.M., Laudadio, M. Preliminary Study for a Landfill Mining Project in Sardinia Proceedings Sardinia 95, Fifth International Landfill Symposium 3 1995: pp. $841-850$.

2. Obermeier, T., Hensel, J., Saure, T. Landfill Mining: Energy Recovery from Combustible Fractions Proceedings Sardinia 97, Sixth International Landfill Symposium 4 1997: pp. 569-578.

3. Quaghebeur, M., Laenen, B., Geysen, D., Nielsen, P., Pontikes, Y., Van Gerven, T., Spooren, J. Characterization of Landfilled Materials: Screening of the Enhanced Landfill Mining Potential Journal of Cleaner Production 55 2013: pp. $72-83$. https://doi.org/10.1016/j.jclepro.2012.06.012

4. Frändegard, P., Krook, J., Svensson, N., Eklund, M. Resource and Climate Implications of Landfill Mining - A Case Study of Sweden Journal of Industrial Ecology 17 (5) 2013: pp. $742-755$. https://doi.org/10.1111/jiec.12039

5. Huang, S.H., Peng, B., Yang, Z.H., Chai, L.Y., Xu, Y.Z., Su, C.Q. Spatial Distribution of Chromium in Soils Contaminated by Chromium-Containing Slag Transactions Nonferrous Metals Society China 19 (3) 2009: pp. $756-764$. https://doi.org/10.1016/S1003-6326(08)60346-5

6. Lind, B.B., Fällman, A.M., Larsson, L.B. Environmental Impact of Ferrochrome Slag in Road Construction Waste Management 21 (3) 2001: pp. 255-264. https://doi.org/10.1016/S0713-2743(00)80037-9

7. Shew, H. RPR Cement Technology. Wuhan: Wuhan University of Technology Press 1991: pp. 36-148.

8. Zhang, X., Zhou, S. The Prospect of Sensible Heat Recovery of Blast Furnace Slag The 7th China Iron and steel annual meeting proceedings, Beijing, China 2009: pp. $11-13$.

9. Nadine, M.P., Parsons, M.B., Seal II, R.R. Characteristics and Environmental Aspects of Slag: A Review Applied Geochemistry 57 2015: pp. 236-266. https://doi.org/10.1016/j.apgeochem.2014.04.009

10. Kalpakjian, S., Schmid, S. Manufacturing Engineering and Technology, Fifth Edition Pearson Prentice Hall, New Jersey, 2006: pp. 790-831.

11. Chong, H., Zhen, W., He, Y., Xiangxin, X. Removal Kinetics of Phosphorus from Synthetic Waste Water Using Basic Oxygen Furnace Slag Journal of Environmental Sciences 30 2015: pp. 21-29. https://doi.org/10.1016/j.jes.2014.11.003

12. Deng-Fong, L., Liang-Hsiung, C., Yu-Kai, W., HuanLin, L. Performance Evaluation of Asphalt Concrete Test Road Partially Paved with Industrial Waste - Basic Oxygen Furnace Slag Construction and Building Materials 78 2015: pp. $315-323$. https://doi.org/10.1016/j.conbuildmat.2014.12.078

13. Chuanbei, L., Laibao, L., Kefeng, T., Lihua, Z., Kaijing, T., Shi, X. Fabrication and Characterization of Porous Cordierite Ceramics Prepared from Ferrochromium Slag Ceramics International 42 (1) 2016: pp. 734-742. https://doi.org/10.1016/j.ceramint.2015.08.174

14. Partha, S.D., Pradip, N., Prabir, K.S. The Effects of Ground Granulated Blast-Furnace Slag Blending with Fly Ash and Activator Content on the Workability and Strength Properties of Geopolymer Concrete Cured at Ambient Temperature Materials and Design 62 2014: pp. 32-39. https://doi.org/10.1016/j.matdes.2014.05.001

15. Bagheri, A., Nazari, A. Compressive Strength of High Strength Class C Fly Ash-Based Geopolymers with Reactive Granulated Blast Furnace Slag Aggregates Designed by Taguchi method Materials and Design 54 2014: pp. $483-490$.

https://doi.org/10.1016/j.matdes.2013.07.035

16. Gencel, O., Gok, M.S., Brostow, W. Effect of Metallic Aggregate and Cement Content on Abrasion Resistance Behavior of Concrete Materials Research Innovations 15 (2) 2011: pp. 116-123

17. Gencel, O., Koksal, F., Brostow, W. Wear Minimisation in Concrete with Haematite Materials Research Innovations 17 (2) 2013: pp. $92-97$. https://doi.org/10.1179/143307511X12998222918877

18. Bilir, T., Yuksel, I., Topcu, I.B., Gencel, O. Effects of Bottom Ash and Granulated Blast Furnace Slag as Fine Aggregate on Abrasion Resistance of Concrete Science and Engineering of Composite Materials 24 (2) 2017: pp. $261-269$.

https://doi.org/10.1515/secm-2015-0101

19. Gencel, O., Koksal, F., Ozel, C., Brostow, W. Combined Effects of Fly Ash and Waste Ferrochromium on Properties of Concrete Construction and Building Materials 29 2012: pp. $633-640$ https://doi.org/10.1016/j.conbuildmat.2011.11.026

20. ASTMG65-04(2010): Standard Test Method for Measuring Abrasion Using the Dry Sand/Rubber Wheel Apparatus, ASTM International, West Consho-Hocken, PA, 2010, 10.1520/G0065-04R10.

21. Pirso, J., Viljus, M., Juhani, K., Kuningas, M. Three-body Abrasive Wear of TiC-NiMo Cermets Tribology International 43 (1-2) 2010: pp. 340-346. https://doi.org/10.1016/j.triboint.2009.06.014

22. Ren, X.Y., Peng, Z.J., Hu, Y.B., Wang, C.B., Fu, Z.Q., Yue, W. Abrasive Wear Behavior of TiCN Cermets Under Water-Based Slurries with Different Abrasives Tribology International 66 2013: pp. 35-43. https://doi.org/10.1016/j.triboint.2013.04.002

23. Stachowiak, G.B., Stachowiak, G.W. The Effects of Particle Characteristics on Three-Body Abrasive Wear Wear $249(3-4)$ 2001: pp. 201-207. https://doi.org/10.1016/S0043-1648(01)00557-9

24. Mikli, V., Käerdi, H., Kulu, P., $\quad$ Besterci, M. Characterization of Powder Particle Morphology Proceedings of the Estonian Academy of Sciences Engineering 7 (1) 2000: pp. 22-34.

25. Yilmaz, K. Investigation of Abrasiveness Property of Blast Furnace Slag on Ceramic Coatings via the Abrasive Slurry Wear Method Tribology Transactions 55 (6) 2012: pp. $762-771$ https://doi.org/10.1080/10402004.2012.709919

26. Hamblin, M.G., Stachowiak, G.W. A Multi-Scale Measure of Particle Abrasivity Wear $185(1-2)$ 1995: pp. $225-233$. 
27. Hamblin, M.G., Stachowiak, G.W. A Multi-Scale Measure of Particle Abrasivity, and its Relation to Two-Body Abrasive Wear Wear 190 (2) 1995: pp. 190-196. https://doi.org/10.1016/0043-1648(95)06624-1

28. Stachowiak, G.W. Numerical Characterization of Wear Particle Morphology and Angularity of Particles and Surfaces Tribology International $31(1-3)$ 1998: pp. $139-157$.

https://doi.org/10.1016/S0301-679X(98)00016-4

29. Suresha, B., Chandramohan, G., Kunigal, N., Ismail, M. Mechanical and Three-Body Abrasive Wear Behaviour of Three-Dimensional Glass Fabric Reinforced Vinylester Composite Materials Science and Engineering A $480(1-2)$ 2008: pp. $573-579$

https://doi.org/10.1016/j.msea.2007.07.011
30. Ren, X., Peng, Z., Hua, Y., Wang, C., Fu, Z., Yue, W., Qi, L., Miao, H. Abrasive Wear Behavior of TiCN Cermets Underwater-based Slurries with Different Abrasives Tribology International 66 2013: pp. 35-43. https://doi.org/10.1016/j.triboint.2013.04.002

31. Antonov, M., Hussainova, I., Veinthal, R., Pirso, J. Effect of Temperature and Load on Three-Body Abrasion of Cermet Sand Steel Tribology International 46 (1) 2012: pp. $261-268$.

https://doi.org/10.1016/j.triboint.2011.06.029 